\title{
I, River?: New Materialism, Riparian Non-Human Agency, and the Scale of Democratic Reform
}

James L. Smith, University of York

[Published in Asia-Pacific Viewpoint (2016), no. 3, pp. 1-13. This is a final pre-press version of the article without editorial enhancement. For the publishers' text with final pagination, please see the DOI at http://dx.doi.org/10.1111/apv.12140.]

\begin{abstract}
This article is a discussion of the 'discourse on the unthinkable' surrounding potential future democratic engagements with rivers as non-human persons or natural objects. In the context of the Asia-Pacific region, this article suggests that the developments in material philosophy entitled 'new materialism' are essential tools in the reconceptualization of rivers as democratic entities, but that local socio-historical conditions must also be taken into the account. In order to make its case, the article surveys the context for considering rivers as non-human persons in a juridical context, but also discusses the new material context that assists modern democracies in the renegotiation of the demos that forms the body politic of democracy-often in the face of neoliberal exploitation and a legacy of extremes in instrumentalism. The article argues the incorporation of water in the democratic project of enfranchisement is an essential exercise born of many western beliefs and ideals, but articulated uniquely at a regional and national level.
\end{abstract}

Some of the terms commonly used to describe water - a supply, a resource, a service - hint at the limitations of our material imagination. Water has had many meanings to many cultures at many times - and 'means' cross culturally among contemporaries — and yet it has become strongly defined by its utility to human society. This revelation has increasingly dominated discourse around the topic of water management in recent years. Water managers may believe that the control of water is necessary for a more sustainable future. They may assert that they can prevent conflict and alleviate human suffering through the prevention of waterbased conflicts, present and future. They may claim that the future of environmental management depends on intergenerational equity, of meeting our needs today without inhibiting the ability of our descendants to meet theirs. All of these positions share the conviction that a new and human-oriented future is the goal, shaped in greater harmony with the environment.

And yet, as this essay will argue, recent trends in philosophy from the movement known as 'new materialism' suggest that although the future of environmental management lies in human perception, it is a human perception of non-human agency that must be approached, interrogated, and ultimately built into the juridical and philosophical underpinnings of western liberal democracy. It is a trend that can remediate the excesses of neoliberal thought, and serve as a conceptual aid to much needed reform. For the Asia-Pacific region, these changes mingle and synergise with unique cultural, political, and philosophical 
traditions to create something new beyond the restrictive boundaries of the past. This essay proposes a global perspective, but one that touches upon this unique context. By exploring some of the emerging legal precedents and philosophical trends that affect the juridical status of natural objects in the twenty-first century, this article offers a new viewpoint for water scholars operating in the Asia-Pacific region and beyond.

What, then, are the unique implications of this global process for the Asia-Pacific region? In December 2007, the Japanese Prime Minister Yasuo Fukada opened the first AsiaPacific Water Summit by quoting the eighteenth-century Japanese scholar Hayashi Shihei, who wrote that "the waters flowing under Nihombashi in Edo and the waters in the rivers in China and Holland are one stream without any barrier" (APWS 2008: 28). The Prime Minister pointed out that Shihei wrote these words to warn Japan of the risk faced from thenalien foreign influences, and yet twenty-first century Japan shares its problems with the AsiaPacific region, and the world. Thus it is for all Asia-Pacific nations: there are exceptional circumstances generated by culture, history, demography and bioregion, and yet part of a larger and fiercer regional and global water future. The solution to such a problem is a democratic conversation undertaken collectively not only between nations, but within the constituent groups found within a nation state.

Water is not wholly passive, inert, or defined by utility, but an agent in a network of agents. In order to embrace this mode of thinking, it is essential that our thinking shift from what Fritjof Capra (1996: 10) has termed 'self-assertive' behaviours-domination, rationalisation, reductionism, linearity-towards 'integrative' behaviours-cooperation, partnership, synthesis, and nonlinearity. Commodification of water is a reflection of a wider trend in neo-liberal commodification, a function of economics and social interaction rather than an inevitable force. As Radin and Sunder (2005: 10) discuss, the forces that emerged in the 50s aided the seminal work of the Chicago school of economics assume that everything is inherently a commodity (used or unused) as a law of nature, even if the prices of different commodities exist implicitly "in the shadows". It is this doctrine that must be contested for water to not always already be a commodity: just as we argue that there are borders to commodification for humans, so too must water be removed from its creep. This is especially relevant to the Asia-Pacific region, where first peoples fight to retain traditional definitions of what is off limits to commodification.

Water is part of human culture, human religion, and daily life, and yet its influence is not a human invention. It is hydro-social, as Erik Swyngedouw (2009) has argued (see Linton and Budds 2014; Schmidt 2014 for new developments of the theory), an entity that is part of our social environment, performing a role that is more profound than is often realised. The part played by water in this environment is not wholly determined by human action, and cannot be regulated wholly by human economic theory. Recent advocates of conceptual change, such as those advocating deep ecology, argue that humanity is but a small part of a wider life-world, a world in which all living things are of equal inherent worth. This essay proposes that institutions of water governance must embrace this approach, but that the imagination of personhood, a form of anthropomorphism and anthropocentrism, has a role to play. 
By reaching beyond the science, jurisprudence, and sociology of water studies and into its material philosophy, I propose, water studies and management tap into a great vein of knowledge that enriches our environmental relationships and imbues natural objects such as rivers with an agency that both protects their ontological parity and provides a familiar interface for political action. A plurality of human relationships with water go beyond its utility, and thus the management of water must also go beyond the limitations of the term 'resource'. Water has become a commodity, and yet it is possessed of traits that raise some troubling questions about prevailing political beliefs. Should a body of water be entitled to rights? What rights should be granted? And perhaps most troubling of all, do these rights entitle a body of water to be considered a person?

Firstly, what do we mean by a 'right'? Jack Donnelly (2013: 8) defines rights as rulegoverned interactions centred on, or under the control of, a right-bearer. The bearer has a right to a thing with respect to a duty-bearer, and the rules enforce who is entitled to claim a right, what the entitlement is, and which parties have a duty to ensure that the right is enforced. Rights are, as Donnelly (2013: 1) asserts before attempting to define them, "historically specific and contingent". The identity of the right-bearer, the nature of their right, and the correlative obligation of the duty-bearer shift with time. Both the ability of water to hold rights and associated personhood must be interrogated for, as Donnelly (2013: 9) points out, "we talk about rights only when they are at issue". Both the identification of natural rights and the identification of the transformation of certain human parties from consumers to duty-infringers is a contestation of the rules, and a historical shift of actants within the transaction of these rules

Legal systems may be willing to accept that all living entities have a moral statusand possible rights - but are they willing to act on this belief on human terms, to bring the democracy of objects into the political ecology? Can the anthropocene epoch experienced by the democratic world tolerate more agential actors, and what are the implications for legal regimes and frameworks? The answers to these questions have a profound impact on the nature of democracy, for humanity runs the risk of disenfranchising entities that are deserving of protection from molestation and harm at the hands of the powerful. As has been the case in the past, reassessment of rights often leads to disturbing but ultimately productive conclusions.

If those with power over water are to create a future political and economic system that is truly just and equitable, then they are morally obligated to critique our understanding of natural objects as democratic entities. Conflict generated by a plurality of values takes place within and between groups of individuals, and within and between different political entities with often conflicting environmental values. In all of these conflicts, the future of environmental thought must be more than an argument between human actors (Smith 2003: 5). Jamie Linton and Jessica Budds (2014: 179) have recently elaborated upon the hydrosocial cycle theory to explore the process of how "water is made known", how it absorbs social relations, power structures and technological interventions which shape society in turn, and how water and society co-produce new hydro-social arrangements. In so doing, they 
reiterate the assertion, which I repeat, that discovering the manner in which democratic deficits and inequalities are produced through water is key to future reform.

Recent years have seen several notable attempts to reassess water beyond its role as a passive and inert element. These include studies from a multi-disciplinary water management perspective (Leybourne and Gaynor 2006), an anthropological perspective (Strang 2009) a philosophical perspective (Macauley 2010), a historical perspective (Linton 2010), and a socio-ecological phenomenon (Chen et al. 2013), to name but a few. In another co-authored publication, I have argued for the narrative legacy of pre-modern water management for the twenty-first century (Morgan and Smith 2013). The renegotiation of the relationship between humanity and its water supply is under way, and the collection of essays in this volume approaches this renegotiation from the perspective of socio-politics. Water is both the catalyst for political conflict and human suffering and the victim of human mismanagement in a constantly shifting cycle, with mismanagement breeding conflict and conflict breeding mismanagement. In order to break this vicious cycle, a reassessment of political identity is required. Michael Mason has proposed that a global institutional and civil society framework is emerging around "established democratic institutions and standards of fairness which suggest... a more inclusive and effective consideration of environmental interests" (Mason 1999: 214). Through the democracy of objects, justice is enhanced and rights expanded so that all may benefit, human and non-human.

\section{Precedents in the Democratic Treatment of River Systems}

The modern intellectual framework is shifting every day as it struggles to re-evaluate our place on this planet, and the future treatment of environment. A struggle takes place at local, national, regional and international level to develop systems of ideation that are cooperative and pan-national, but also culturally appropriate. Water has become implicated in this process, for it is malleable and yet extremely easy to mismanage. Much of this mismanagement has occurred due to the misapplication of ideas (scientific, philosophical, or political) outside of their appropriate context, and the solution must avoid the same mistake. Water brings life and yet engenders conflict; it allows agriculture and yet carries toxic runoff throughout diverse ecosystems and biospheres. All peoples share in the risks and rewards, and yet the solution is more complex than unilateralism or localism. The philosophical focus has shifted from a feeling of hydraulic mastery to an uncertainty, a sense that the fate of humanity is intermingled with that of water in a manner not fully understood. Water has moved from abstraction into a very real permeation of consciousness, as Jamie Linton (2010: 6) argues:

No longer taking water for granted in a material sense, we have also begun to think about water in a different way. Water is now more complicated than it seemed in the mid-twentieth century. In modern times water has most commonly been thought of as a resource that could be considered and managed in abstraction from the wider environmental, social, and cultural context(s) in which it occurred. Today, however, water is complicated by (and co-implicated with) these contextual circumstances. 
The potential consequences of this co-implication are particularly significant in the realm of political action, bioethics, and jurisprudence. Further tools are needed to aid in the confrontation of our future water democracies. In this essay, I present a case for the treatment of river systems in a more democratic fashion, as discrete entities deserving of certain rights, privileges, and protections under the law. The western intellectual tradition has a historical and a theoretical legacy that are both the cause, and the partial solution, to the mistreatment of water resources. There is great potential for compromises and redefinitions in the issue of water as a democratic entity. Water is an actor within a political ecology, a participant in a complex series of interactions that influence human life on a civic and individual level. Natural entities are actors in this ecology, and greater awareness of their powers leads to more balanced human interactions with the environment. Natural objects occupy a position which may cause interaction and antagonism between human and non-human, as Paul Robbins describes:

...following thinking in science studies and related fields, it is increasingly clear that non-humans are collaborators in complex relationships, influencing people and institutions and setting the terms of economic growth and political change. Conversely, however, the qualities of non-humans that are incongruent with state organization, capitalist accumulation, and various forms of social institutions cause them to resist or create friction with human activities, producing a different kind of political engagement (Robbins 2012: 232).

When apprehended as an actor in a political ecology, it is increasingly clear that the democratic role of water has become divorced from its political potential. Water has the power to exert political power, and yet it lacks the representation and definition of a person that might allow it to do so. In the absence of this particular form of political agency water "flows to power", as Erik Swyngedouw has boldly stated. Societies with power are never in want of water, for they have the means to exert influence over hydrological resources. The control of water, in turn, brings power (Swyngedouw, 2006: 57). But what if the power that drove water were not the power of humans, but the power of its own positive freedom, the power to remain intact, unmolested, and whole? It may seem implausible to advocate for the agency of natural objects such as rivers in an era when a vast number of human beings are denied rights and others flout their power. And yet, as this article argues, the advocacy of non-human personhood is not a replacement for human rights advocacy, but a complementary process in which both human enfranchisement and natural enfranchisement can be mutually supportive.

Rivers have long been valued through myth, story, and allegory as non-human persons: they are participants in a story of creation and regeneration, actors in a global network of creative forces, and companions in life-worlds lacking a human monopoly on agency. These entities exist today in the cultures of many first peoples, in the cultural engagements of everyday life, in the histories of human interconnection with the hydrological cycle. This article seeks to place the modern quest for greater equity and justice within water policy within this tradition. Philosophy and critical theory, too, offer rich insights that bear scrutiny. The incipient trend in 'new materialism' within the humanities (philosophy, critical 
theory, intellectual history) has highlighted the necessity for non-human agency and autonomous force in the face of degradation and exploitation. In her monograph Vibrant Matter, for example, political scientist Jane Bennett (2010: vii) has argued that a more nuanced understanding of what she terms the 'vibrant materialism' of objects is required in order to counteract the neoliberal idea of matter as "passive stuff, as raw, brute, or inert".

Rivers are one of the more obvious candidates for personhood: they are expansive, mysterious, powerful, and agential. They are complex but complete, balanced and yet changeable. Their flow metaphorically bonds us of our own bodies, the flow of blood in our veins. They are repositories of stories, myths, and culture. They have a powerful influence on human life for good or ill, wending through natural and political ecologies. Environmental Philosopher David Macauley has called for a recuperation of nature as a powerful and formative force by returning to certain pre-modern notions of interaction. In Macauley's case, the interactions are those of the four Classical elements, Earth, Air, Fire, and Water. Macauley (2010: 2) calls for an anamnesis, a loss of forgetfulness, in our interaction with the environment:

The elements often appear dimmed down or diminished as they enter the human domus. Although physically near, they nevertheless remain existentially remote, covered over, or concealed. One task, then, of ecological philosophy is to encourage a renewed understanding of and critical encounter with air, fire, earth, and water and to make us aware of the complex - and sometimes very necessary-mediations that exist between us and the environment, between humans and a more capacious world.

The forgetfulness prompted by vast new discoveries in the sciences extends into many premodern ideas, and the personification of rivers and their fellow natural entities is no exception. Just as western thinkers often have forgotten that the elements combine to shape our imagination and lives on a scale that is ecologically meaningful, so too is the population of nature with new 'people' a past idea that, when remembered, may be remediated and transformed in the present and in the future. Some cultures, however, have never forgotten. It is their precedent, coupled with developments in western thought, that can inspire democratic thought anew.

When human beings are denied their rights, there is an implication of wrongdoing, of an undemocratic trend. Ignorance, hypocrisy, complacency, or naiveté may cause the privileged and powerful to ignore these breaches, but a sense of their injustice remains. For natural entities, there is a denial of agency so strong that many still struggle to comprehend the possibility of rights for nature comparable to our own, be they theoretical or in actuality. An abused person is a victim, and yet an abused environment is degraded. Humans often care about the destruction of natural entities, but because they are beautiful, unique, or irreplaceable. Modern observers care because their absence is a death sentence for the human race. They care because human quality of life is curtailed, and the future darkened. But what if contemporary societies could care because all persons, be they natural or juridical, are rights-bearing and thus deserving of protection? 


\section{The Riparian 'Discourse on the Unthinkable'}

In a 1972 article entitled 'Should Trees have Standing?: Towards Legal Rights for Natural Objects', Christopher D. Stone established an argument that was purely speculative, and yet based on promising developments in legal precedent. The article - still in print as of 2010 in a $35^{\text {th }}$ anniversary compilation by Oxford University Press - continues to serve as the seminal study on its subject matter. Natural objects such as trees, rivers, oceans and mountains should have rights under the law, become juridical persons in the manner of the corporation or government. Furthermore, as Stone's expanded research (2010) revealed, other natural objects such as the climate and the ocean were worthy of consideration. Stone proposed an inchoate argument for a form of 'Earth jurisprudence', a reordering of political entities that places the rights of nature back into focus (Brenan 2013). Within western legal and moral discourse, Europeans once considered non-Europeans as inferior by virtue of Biblical narrative - thus morally justifying exploitation - and women were considered emotional and illogical by men - and thus not able to exercise the right to vote. Today many individuals and institutions struggle to apprehend natural objects as being eligible for moral status and its attendant rights, or able to benefit from them. The process is well underway, and yet new neoliberal thinking with its associated economic instrumentality threatens to drown out the voices of those opinions aired since the 1970s, when the debate began in earnest.

The mechanistic worldview is persistent. If the New Materialist philosophies to be discussed below have something to teach us, it is that human beings are not the sole agents in our environment, nor is their distinctness as corporeal entities unique. Humans have reserved these powers for themselves, and yet can no longer afford to discount the power of nonhuman forces. The disbelief in non-human agency, fuelled with the mechanistic notions born from the Enlightenment, has created a catch twenty-two scenario. No rights without value, no value without rights:

There is something of a seamless web involved: there will be resistance to giving the thing "rights" until it can be seen and valued for itself; yet, it is hard to see it and value it for itself until we can bring ourselves to give it "rights--which is almost inevitably going to sound inconceivable to a large group of people (Stone 1972: 9).

Stone argued that "until the rightless thing receives its rights, we cannot see it as anything but a thing for the use of "us" - those who are holding rights at the time" (1972: 9). An object or entity remains a 'thing' until the possibility of it being enfranchised and protected by rights is no longer unthinkable. For us to believe that an entity might be deserving of rights and privileges similar to those enjoyed by natural persons such as human beings, it must first be conceded that it has agency, and that this agency is being infringed upon by our mistreatment of the entity. It is not enough to decry the pollution and ecological damage caused by environmental mismanagement because they negatively impact upon our lives: modern societies must move to a stage of thought in which they look upon these mistreatments as they would look upon the mistreatment of a human being.

As Thomas Berry (1999: 82) put it, we must move away from the perception that the universe is a "collection of objects", and towards to view that it is a "communion of 
subjects". Modernity must make the intellectual leap from the notion that all human life is deserving of legal protection, past the idea that entities such as animals have rights, and into a state of discourse in which natural objects may be included. Jamie Linton (2010: 7) has argued that water has a long history as a participant in our political thought-world, and yet continues to challenge us:

...we cannot ignore water's political dimensions, as marked by the distribution of economic benefits and affordances associated with particular modes of water governance. These various dimensions have always been present in water, of course. Now, however, the ecological, cultural, and political aspects of water present themselves to us in ways that challenge and defy our abstract understanding of water's nature (Linton 2010: 7).

Water as a political entity is in the process of being redefined. Rivers form an ideal case study in this discussion, for there is evidence that a reassessment of their role in our democratic imagination is underway. This precedent has moved beyond theory, and entered the realm of the law and of governance. The beliefs of traditional societies around the world retain a respect for, interaction with, and veneration of natural entities that has started to influence the dominant ideologies that have led to environmental degradation and, most recently, climate change. The answer, however, is a series of local stories that are often defined in terms of their interaction with local beliefs and cultural contexts.

\section{Global Precedents: Water Democracy in (In)Action}

In 2012, the New Zealand Ministry for treaty negotiations made a ruling that the Whanganui river, third longest in the country, was recognised by law as a legal person, individual and entitled to certain rights. This enshrined in law the aspiration of the 1999 Whanganui River Report that the river should be viewed as integrated and indivisible "in both biophysical and metaphysical terms from the mountains to the sea" (Record of Understanding 2011: 1.18.1). In this case, the river has become a juridical person deserving of rights by virtue of the cohesion of its parts into a legal whole. This is a positive step not only for the recognition of the Māori Whanganui Iwi as custodians of the river, but is a positive precedent for global democratic reform. Anthropologist Veronica Strang has recently argued that the case of New Zealand is an important precedent in the bioethical inclusion of indigenous voices into the conversation of water management:

[A] more egalitarian bioethical position draws inspiration from some of the indigenous worldviews...in which the nonhuman is seen to have agency and power, and thus to occupy a collaborative position in relation to human societies. In the colonial appropriation of indigenous land and resources, such subaltern worldviews have been subsumed but, as the events [in New Zealand] illustrate, they resurface in debates about the ownership and management of water (Strang 2014: 121-122).

New Zealand is a prime example of the struggle beginning to take place within the AsiaPacific region. Scholars such as Brad Coombes (Smith and Coombes 2012; Coombes 2013) and Gail Tipa (Tipa and Panelli 2009; Tipa and Nelson 2012) have explored struggles 
between neoliberal shortcomings in urban planning and water management and Māori knowledge and beliefs, and proposed ways in which indigenous knowledge and agency can reshape the debate. Examples from other countries in the region demonstrate the emergence of local beliefs in the water management challenges and crises of the twenty-first century. In the Buddhist region of Ladakh in Northwest India, for examples, severe flash floods have been understood in the context of karmic retribution coupled with the retribution of an agentic and sentient landscape (Butcher, 2013). As Andrea Butcher (2013: 104-105) has argued, these local beliefs are a key part of large-scale solutions, and cannot be ignored:

...narratives linking climate change with shamanic belief and pollution concerns help to reveal the localized and contextualized explanations of disaster and environmental management in transforming landscapes in ways that empirical ecology studies cannot accommodate.

The local socio-religious contexts of diverse peoples have a direct effect on the reaction to and management of water. The question is this: how can these perspectives and beliefs be incorporated into legal and democratic responses? It is useful to observe an example of a democratic principle enshrined in law, tested in practice, and realised in the courts in a landmark decision. The Whanganui Iwi have guaranteed the future consideration of their river as a democratic entity, but we must turn to South America to see what such a decision can achieve with time.

The Vilcabamba river in Equador has been protected from misuse as the result of a 2008 constitutional reform mandating the legal rights of nature. This protection was tested in response to environmental degradation caused as a result of extensive road works undertaken by the Provincial Government of Loja. The defendant was accused of dumping large quantities of excavation material in the nearby river while excavating a large regional highway. The provincial court passed constitutional injunction 11121-2011-0010, establishing the need for the road works to be conducted on the basis of the precautionary principle, placing the burden of proof on the local authorities to demonstrate that they were not causing morally unacceptable harm that was scientifically plausible but uncertain (Beder 2006: 48). The damage to the river was deemed to be irreversible and inequitable to future human generations, but was also deemed to be harmful to the continued existence of the river. The rights of the local population to proper infrastructure and the mandate of the local authorities to provide it were balanced against the rights of the river to integrity, the flow of which had been halved by careless and unregulated dumping (Greene 2011).

By acquiring legally mediated access to representation, rights, and justice under the principles of liberal democracy long accorded to incorporated entities, the Whanganui and Vilcabamba rivers have gained powerful protection from the instrumentalist effects of neoliberal exploitation. A quasi-corporeal legal representation of hydrology has the ability to not only shape a more sustainable and culturally equitable relationship with riverine systems, but to counter the reduction of water into exploitable base components. Just as a corporation is able to act in a political ecology due to the collective juridical personhood of its constituent human members, so too must other rivers be legislated into personhood, joining those rivers 
that are now classified among the ranks of the legally enfranchised. Water has a compelling case for personhood, a role that it has held de facto at many times in the past.

For water to become a democratic person de jure, democratic societies must reassess their ethics when it comes to the classification of the people, the demos, whom they wish to include in their communities. If democracy - at its core, and independent of any particular permutation-promotes both opportunities for self-determination and moral autonomy (Diamond 1999: 3), then it should extend these affordances to new members. A solution by democratic means, however, is not simple: democracy is linked to the history of the very perversities that it seeks to address - the applicability of Western Democracy to a select few and its denial to others, its aggressive displacement of existing modes of social interactionand yet it has the capacity to remediate. It is also important to note that it was liberal democracy and its emphasis on individual freedom that enabled neoliberalism, its addiction to commodification, and its creation a flattened environment lacking in vitality. The vibrant materialism that Bennett seeks cannot be fostered by the same ideas that deadened matter in the first place. The assertion that we must "recover" vitality through the apparatus of the nation-state is a repetition of colonial discourse, and excludes traditions outside of this worldview (Schmidt 2014: 203). Nor do all participants of a democracy have equal engagement in a world where resources buy influence in an environment of neoliberal "responsibilisation", as Smith and Coombes (2012) demonstrate in the case of New Zealand's environmental planning. Environmental responsibility should not be a function of personal agency alone. Democratic evolution must overcome these contradictions and perversities, and must involve the local positions and beliefs outlined by Strang (2014).

South America would not be leading the world in radical legal re-definitions of nature were it not for unique national and regional political and cultural beliefs shaping democracy. Evolution requires the right to acknowledge and validate the autonomy of the non-human is an expression of culturally situated moral autonomy that is both shared by all democracies, but also drawn from diverse voices and knowledges. The stakes are high, and yet the leap in logic from human rights and democracy to non-human rights and democracy must cross a vast chasm. Only now, at the time of writing, has it become conceivable that non-human animals such as simians might be treated as legal persons, entitled to habeas corpus and fundamental rights of bodily liberty. The Nonhuman Rights project is arguing that "once [they] prove that chimpanzees are autonomous, that should be sufficient for them to gain legal personhood and at least have their fundamental interests protected by human rights" (BBC 2013). However, the NRP case for simians as non-human persons has recently hit a legal stumbling block in the USA with the 2014 ruling that Tommy the chimpanzee cannot be considered a legal person because "...unlike human beings, chimpanzees cannot bear any legal duties, submit to societal responsibilities or be held legally accountable for their actions" (BBC 2014 1). In Argentina, however, Sandra the orang-utan was recently released from captivity after being granted limited human rights (BBC 2014 2). Both cases have aroused suspicion and scepticism from the media and lawmakers alike, and yet it was a unique Argentine context that allowed Sandra to be emancipated where Tommy was disenfranchised. Simians, at least, have their human ties to protect them, a body of their own 
to define them. Aqueous entities may not suffer pain and emotional trauma as animals do, and yet their autonomy is an equally valid indicator of their need for legal protection. In both cases, political action is required. In the case of water, decision makers must re-evaluate their very abstract imaginations before they are able to act, to discourse on the topic of the unthinkable. In this discourse, regional factors are key.

Conversely, my argument here to scholars of and in the Asia-Pacific region is that the non-human rights of aqueous entities such as rivers as shaped not only by unique cultural phenomena, but by a global legal and philosophical struggle. In addition, the peculiar legacy of European colonialism and cultural influence in the region has left its mark on the water management framework, and that understanding the historical perversities and problems of a problem born from western thought offers the key to local solutions. The democracy of objects is the intellectual by-product of western intellectual history, and yet it offers a framework for culturally unique solutions. The rivers of thought that flow from the font of democratic history and tradition are the same as those that flow through the Asia-Pacific, and yet water management merges local solutions with global frameworks. Democracy is both a cause and a solution, but not in the way that those caught up in the logic of nation-states, economies, and human actors might believe.

\section{The Democracy of Objects: New Materialism as Political Intervention}

Recent shifts in the philosophy of environment have initiated a move of focus from the human relationship to a series of inert natural objects towards what Jane Bennett has termed a vibrant materialism. By acknowledging that matter is active and agential and not inert, philosophical discourse can shift the future of environmental democracy away from better utilisation of resources, and towards better co-existence within a political ecology consisting of many human and non-human actors. This is an essential context for our discussion of objects as non-human persons, for the first step in the reform of our democracy and jurisprudence must stem from a belief that natural objects are entities worthy of interface rather than use. This cannot occur until the majority recognise that environmental management goes beyond the neglect of natural resources in favour of neoliberal growth, and into the understanding that humans are not abusing 'stuff', but denying the existence of agency.

The birth of the problem-together with the problem of neoliberalism and commoditisation-lies in western humanism. As Graham Harman (2009: 59) discusses when exploring Bruno Latour's We Have Never Been Modern, the tradition of humanism and of the enlightenment created a "Copernican" effect, placing humans in the centre of the ontological cosmos, making all other things "stupid robotic objects acting with clockwork mechanical torpor". Latour proposed a counter-revolution, introducing Actor-Network theory as a denial of separation between human and object. A child of Latour in many ways, the trend in New Materialism has a great deal to teach us about the intermingling of bodies, and of identities, that constitute our political and natural environments. The production of new democratic and hydro-social patterns that overcome the enlightenment reification of the subject is a 
philosophical solution that may be seen as a self-correction of European thinking on the matter.

The realisation that the material environment infuses, influences, is the body, leads to a new form of environmental politics, a system in which nature must be recognised not only as a power, but as part of the human world at a level beyond the human scale of comprehension. Before it is possible that natural objects can be juridical persons, it must first be understood that they can be bodies, whole and integrated. Just as human bodies are conglomerations of parts working as an organism, so too are natural entities possessed of an integrity rendering them eligible for consideration in our democratic system. As Diana Coole and Samantha Frost have argued, a new materialist perspective forces us the reassess the political forces at work in out interactions with the environment:

Paying attention to corporeality as a practical and efficacious series of emergent capacities thus reveals both the materiality of agency and agentic properties inherent in nature itself. Both have important implications for the way we understand political processes (Coole and Frost 2010: 20).

Mindfulness of non-human objects as agents extends corporeality beyond that of our own human bodies alone, leading to consideration of the countless entities that populate and influence human life. The demos - the unit of interest and of influence within a democracyexpands to include not only distinct and visible bodies, but the countless interactions that take place within. It is more than its parts, an irreducible whole. As a result, all actors within this demos must be accounted for as part of a collective will. The demos is not a fixed and codified set of actors, but a seething mass of natural objects, and the objects that compose these objects. This non-human world is not only made up of composite objects at a visible scale such as trees, rivers, or mountains, but on a vast continuum from the smallest atom to the vastest cosmic bodies:

Consider, for example, the way [a materialist theory of democracy] imagines the being of the demos: not as a formed thing or fixed entity, but as an unruly activity or indeterminate wave of energy. The demos is, we read, "neither the sum of the population nor the disfavored element within," but an "excess" irreducible to the particular bodies (Bennett 2010: 106).

The alliances of elements that compose the discrete emergent wholes of objects, legal entities, and democratic corpora are irreducible: they cannot be 'undermined' to the atoms, molecules, and cells that make up their bodies, nor can they be dismissed as manifestations of a greater whole. They are a democracy of objects, each potent in diverse ways, each adding together to make a new form of democratic body, a composite alliance of forces. Legal personhood is an essential tool within such a world, for it collects assemblages of objects together into blocs that are both indivisible and plural. A river is indivisible and plural, just like the human body, for it is indivisible and plural by virtue of its ecological cohesion. As Jane Bennett argues, democratic humans act in alliance of this greater demos, and must learn 
to think of political action in corporate terms. Not only are certain objects allied into a unified form, but our life on earth is likewise a conglomeration of human and non-human:

If human culture is inextricably enmeshed with vibrant, nonhuman agencies, and if human intentionality can be agentic only if accompanied by a vast entourage of nonhumans, then it seems that the appropriate unit of analysis for democratic theory is neither the individual human nor an exclusively human collective but the (ontologically heterogeneous) "public" coalescing around a problem (Bennett 2010: 108).

Before humanity can move towards a historical understanding of personification and its future within environmental democracy, it must first break with the assumption that the human is the only subjects worthy of power. The practice of political power involves the imagination of what constitutes a political agent, and theorists such as Bennett are pushing at the boundaries of the categories managing our imagination of agency. The implication of this agentic expansion, it seems, is a shift from the centre of action away from the domain of the human being. Karen Barad has argued that this shift is the first step to a new politics of human and non-human:

The specificity of intra-actions speaks to the particularities of the power imbalances of the complexity of a field of forces. I know that some people are very nervous about not having agency localized in the human subject, but I think that is the first steprecognizing that there is not this kind of localization or particular characterization of the human subject is the first step in taking account of power imbalances, not an undoing of it (Barad 2012: 55).

The question that looms in the case of water management is one of power, and of agency. How does an aqueous entity such as a river, lake, or underground aquifer fit into our political discourse? When decision makers attempt to answer such questions, it is essential for their priorities to be clear. Do they wish to manage environment, or do they wish to include environment in their decision making processes, to take account of its best interests as an intrinsic right? Levi Bryant reveals the stark reality of this decision:

An activist political theory that places all its apples in the basket of content is doomed to frustration insofar as it will continuously wonder why its critiques of ideology fail to produce their desired or intended social change. Moreover, in an age where we are faced with the looming threat of monumental climate change, it is irresponsible to draw our distinctions in such a way as to exclude nonhuman actors (Bryant 2011: 24).

Bryant makes a compelling point. If our democratic system fails to account for the influences of countless agents beyond the scope of the human, then political solutions will fail due to an ignorance of variables. Modern thinkers must understand some of the forces at work in the redefinition of environmental matter, and must also consider the network of interactions that blur the boundaries between human subject and natural object. If they fail to do so, they will be unable to implement policies, make political decisions, or postulate philosophical solutions that are true to our place in the life-world that surrounds us. Humanity may be 
powerful and intentional, but it is not alone in its natural personhood. Finally, we would do well to note that the language of democracy as an apparatus of the nation-state is not an inevitable discourse, and is in fact a colonialist impulse that we would do well to avoid (Schmidt 2014: 230): listening to a wider democracy of object and a wider community of cultural beliefs means

I propose that the imagination of objects as non-human agents is greatly aided if democracy can adapt their agency into its current intellectual frameworks, to imagine their personhood. This is not an argument that natural objects such as rivers think or intend, but that they move, connect, act with such far-reaching political ramifications that human observers must imagine them as persons, rights-bearing, corporeally complete, and part of the demos of democracy. Those of us steeped in western thought have forgotten the possibility of this imagination, and thus the section to follow recuperates it through its history, alteration, and afterlives in the twenty-first century. For those beyond the West - in the Asia Pacific region, in this context - the solution lies not only in pan-national decision making, but also in the recuperation of cultural beliefs that enshrine the co-mingling of human and non-human, and the agency of the natural world. Perhaps, once the materialisms of the East and West combine, something new can be born that merges the best democratic ideals of all.

\section{Conclusion: Democracy for Natural Objects?}

Christopher Stone has been vindicated by history in his 1972 assertion that we should treat natural entities as legal entities. He called for a new myth of environmental consciousness, in which a scientific and ecological understanding of human nature would lead to the treatment of natural objects as part of our own body, our life support system:

...I do not think it too remote that we may come to regard the Earth, as some have suggested, as one organism, of which Mankind is a functional part - the mind, perhaps: different from the rest of nature, but different as a man's brain is from his lungs (Stone 1972: 52).

As we have seen, environmental philosophy has moved on from this perspective, arguing not only that natural entities are part of our global life support system, but that humanity need not be the mind of the planet, should see itself as primus inter pares rather than as guiding intelligence. Humans may be the species possessed of the greatest intentionality, but this does not automatically entitle us to the most power, nor should humans only care for the rights of nature when it is in our interests to do so. A healthy democracy of objects is both within us and without us: where does the body end and the environment begin? Human life composes, and is composed by the environment, and the acknowledgement of this reality will bring holistic benefits.

The democracy of objects offers the intellectual catalyst needed to confront the unthinkability of riparian personhood, and its enshrinement in our juridical frameworks. This will be and must be an on-going conversation, and yet the tools that will enable its resolution or evolution reside in all corners of discourse. The collected disciplines of the Humanities have their own perspectives to add to this conversation, informing the growing sociological, 
scientific, policy, and juridical developments that continue to enrich the study of water. Future human life on Earth cannot continue without reforms to environmental management, and these reforms would be impoverished if non-human entities were excluded from the ranks of the enfranchised. Just as it is necessary to reform democracies failing to cater for the needs of their citizens, so too must the international legal framework expand the list of those to be catered for. A person, natural or juridical, has intrinsic rights regardless of their ability to contribute in the discourse of power. If a human being is treated in an unjust and unrepresentative fashion, lawmakers would likely consider this to be a failure of the democratic process. It is now necessary to push through a perceptual paradigm that does not apply the same logic to the non-human world. Bringing natural entities into the multitude strengthens the body politic, and creates a more vigorous future democracy. Human life on Earth stands and falls with the environment, and all democracies must account for this reality within the framework of the law.

Human cultures - in diverse forms - invest emotional energy in bodies of water. In a region such as the Asia-Pacific where water is both lifeblood - the great rivers of East and South-East Asia — and dangerous destroyer - the typhoon, the flood, the tsunami-fear and respect have led to potent personifications. The journey to new modes of personhood continues. As this journey progresses, water must become more than a neoliberal resource, more than an object of western law and philosophy, and more than the generic homogenisation of culture that results from rampant globalisation. Many voices must be heard, those previously subaltern peoples, faded cultural ideologies, and alternate human and natural democratic ideals. The problem of water democracy is global, and yet the solution is partially be regional and local. New hydro-social arrangements require a nuanced balance between sweeping reform and local difference, between the overarching mechanisms of capitalism and democracy, and social transactions that respect the history of the hydro-social cycle (Schmidt 2014) and its regional and cultural plurality (Strang 2014).

There is a further step that legislators may take beyond the recognition of natural objects as juridical persons, and it may continue to be a challenge for many years to come. Beautiful natural entities have an advantage, because humans are motivated to care for them by our innate sense of biophilia. Cute animals appeal to us, for example, because they remind us of our own young, and thus we feel affection for them. Humans feel affective ties to flora or fauna that are pleasing to the eye or fascinating to science, but what of the ugly and the abject? Is an entity that is displeasing to a human being by virtue of its appearance or behaviour any less deserving of protection? What of the parasites, the weeds, the hideous denizens of the ocean trenches, or those members of the animal or plant kingdom that behave in a manner that a society or societies abhor? Perhaps the process of legal enfranchisement will help in this respect, as will an increased awareness of diverse cultural beliefs, for an entity with rights cannot be mistreated or ignored in the same way as forms of life that are both distasteful and uninteresting to humans. This may be the next great discourse on the unthinkable, equally dependent on global and local factors for success. 


\section{Bibliography}

Barad, K. (2012) "Matter feels, converses, suffers, desires, yearns and remembers": Interview with Karen Barad, in R. Dolphijn \& I. van der Tuin (eds) New Materialism: Interviews \& Cartographies. Ann Arbor, Michigan: Open Humanities Press, University of Michigan Library.

BBC News: Latin America and Caribbean (2014) Court in Argentina grants basic rights to orang-utan. Retrieved 1 April 2015, from website: http://www.bbc.co.uk/news/worldlatin-america-30571577 (2)

BBC News: US and Canada (2013) NY court asked to give chimpanzee 'legal person' status. Retrieved 1 April 2015, from website: http://www.bbc.co.uk/news/world-us-canada25211859

BBC News: US and Canada (2014) US chimpanzee Tommy 'has no human rights' - court. Retrieved 1 April 2015, from website: http://www.bbc.co.uk/news/world-us-canada30338231 (1)

Beder, S. (2006) Environmental Principles and Policies: An Interdisciplinary Introduction. London: Earthscan.

Bennett, J. (2009) Vibrant Matter: A Political Ecology of Things. Durham, North Carolina: Duke University Press.

Berry, T. (1999) The Great Work: Our Way into the Future. New York: Bell Tower.

Brenan, T., The Ecologist (2013) Recognising the Rights of Nature,. Retrieved 1 April 2015, from website:

http://www.theecologist.org/blogs_and_comments/commentators/other_comments/179664 7/recognising_the_rights_of_nature.html/

Bryant, L. R. (2011) The Democracy of Objects. Ann Arbor Michigan: Open Humanities Press, University of Michigan Library.

Butcher, A. (2013) Keeping the Faith: Divine Protection and Flood Prevention in Modern Buddhist Ladakh. Worldviews, 17: 103-114.

Capra, F. (1996) The Web of Life: A New Synthesis of Mind and Matter. London: HarperCollins.

Chen, C., J. MacLeod \& A. Neimadis (eds) (2013) Thinking with Water. Montreal: McGillQueen's University Press.

Coombes, B. (2013) Māori and Environmental Justice: The Case of "Lake" Otara, in E. Peters \& C. Anderson (eds) Indigenous in the City: Contemporary Identities and Cultural Innovation. Vancouver: University of British Columbia Press. 
Coole, D. \& S. Frost (2010) Introducing the New Materialisms, in D. Coole \& S. Frost (eds) New Materialisms: Ontology, Agency, and Politics. Durham, North Carolina: Duke University Press.

Diamond, L. (1999) Developing Democracy: Towards Consolidation. Baltimore, MD and London: Johns Hopkins University Press.

Donnelly, J. (2013) Universal Human Rights in Theory and Practice. Ithaca, NY and London: Cornell University Press.

Greene, N., Global Alliance for the Rights of Nature (2011) The first successful case of the Rights of Nature implementation in Ecuador. Retrieved 1 April 2015, from website: http://therightsofnature.org/first-ron-case-ecuador/.

Harman, G. (2009) Prince of Networks: Bruno Latour and Metaphysics. Prahan (Victoria, Australia): re.press.

Leybourne, M. \& A. Garnor (eds) (2006) Water: Histories, Cultures, Ecologies. Perth: University of Western Australia Press.

Linton, J. (2010) What Is Water?: The History of a Modern Abstraction. Vancouver: University of British Columbia Press.

Linton, J. and J. Budds (2014) The hydrosocial cycle: Defining and mobilizing a relationaldialectical approach to water. Geoforum, 57: 170-180.

Macauley, D. (2010) Elemental Philosophy: Earth, Air, Fire, and Water as Elemental Ideas. Albany, New York: SUNY Press.

Mason, M. (1999) Environmental Democracy: A Contextual Approach, London: Earthscan.

Morgan, R. A. \& J. L. Smith (2013) Pre-Modern Streams of Thought in Twenty-First Century Water Management. Radical History Review, 116: 105-129.

Radin, M. J. \& M. Sunder (2005) Introduction: The Subject and Object of Commodification, in M. M. Ertman \& J. C. Williams (eds) Rethinking Commodification: Cases and Readings in Law and Culture. New York and London: New York University Press.

Robbins, P. (2012) Political Ecology: A Critical Introduction. Hoboken, NJ: John Wiley and Sons.

Schmidt, J. J. (2014) Historicising the Hydrological Cycle, Water Alternatives 7(1): 220-234.

Secretariat of the $1^{\text {st }}$ Asia-Pacific Water Summit (2008) The Proceedings of the $1^{\text {st }}$ AsiaPacific Water Summit, Singapore: World Scientific.

Smith, C. and B. Coombes (2012) Washing Their Hands of It? Auckland Cities' Risk Management of Formerly Horticultural Land as Neoliberal Responsibilisation, in T. 
Taşan-Kok \& G. Baetan (eds) Contradictions in Neoliberal Planning: Cities, Policies, and Politics. Dordrecht: Springer.

Smith, G. (2003) Deliberative Democracy and the Environment. Oxford: Routledge.

Stone, C. D. (1972) Should Trees Have Standing?: Toward Legal Rights for Natural Objects. Southern California Law Review, 45: 3-52. See also (2010) Should Trees Have Standing?: Law, Morality, and the Environment. $3^{\text {rd }}$ Edn. New York: Oxford University Press USA.

Strang, V. (2009) Gardening the World: Agency, Identity and the Ownership of Water. Oxford, New York: Berghahn Books.

Strang, V. (2014) The Taniwha and the Crown: defending water rights in Aotearoa/New Zealand, WIREs Water, 1: 121-131.

Swyngedouw, E. (2006) Power, Water and Money: Exploring the Nexus, Human Development Occasional Papers (1992-2007). New York: Human Development Report Office (HDRO), United Nations Development Programme (UNDP).

- (2009) The Political Economy and Political Ecology of the Hydro-Social Cycle. Journal of Contemporary Water Research \& Education. 142(1): 56-60.

Tipa, G. and K. Nelson (2011) Environmental Flow Assessments: A Participatory Process Enabling Maori Cultural Values to Inform Flow Regime Setting, in B. Rose Johnston (ed) Water, Cultural Diversity, and Global Environmental Change: Emerging Trends, Sustainable Futures? (UNESCO IHP) Dordrecht: Springer.

Tipa, G., R. Panelli and Moeraki Stream Team (2009) Beyond 'someone else's agenda': An example of indigenous/academic research collaboration, New Zealand Geographer. 65(2): 95-106.

Whanganui Iwi and The Crown (2011) Record of Understanding in Relation to Whanganui River Settlement. Retrieved 1 April 2015, from website: http://www.wrmtb.co.nz/new_updates/Record\%20of\%20Understanding\%202012.pdf 